\title{
Outcome of Seton in the Management of Complex Fistula in Ano in a Tertiary Care Center in Bangladesh
}

\author{
Islam MA ${ }^{1}$, Khan $\mathrm{MMR}^{2}$, Rahman $\mathbf{M M}^{3}$, Akther $\mathrm{SMQ}^{4}$, Hoque $\mathbf{M M}^{5}$, Reza $\mathrm{SM}^{6}$, Anowar $\mathrm{AB}^{7}$, Akhter $\mathrm{S}^{8}$
}

Conflict of Interest: None

Received: 20.01 .2020

Accepted: 16.02 .2020

www.banglajol.info/index.php/JSSMC

Key Words:

Complex fistula in ano, Seton therapy

\begin{abstract}
:
Background: The management of high and complex anal fistulas remain a therapeutic challenge as it is often associated with recurrence and anal incontinence. The oldest and theoretically the simplest technique is to use a seton. The aim of this study is to find out the outcome of seton in the treatment of complex fistula in ano.
\end{abstract}

Materials and methods: This cross-sectional study was done in surgical units of ShSMCH and colorectal surgery units of BSMMU from September 2014 to August 2015. Fifty patients with high anal fistula having internal opening above dentate line and with multiple fistulas tract were included by purposive sampling. Patients with low anal fistula, fistula in ano associated with Crohn's disease, active abdominal tuberculosis, carcinoma of rectum, previous radiation therapy, with recurrent fistula in ano and in whom the internal opening could not be located were excluded. After initial evaluation, the fistula tract and opening were located. The skin and anoderm overlying the fistulous tract were incised. This double-strand seton was then tied over itself on the sphincter without excessive tension. The long end of each suture was tapped to the patient's medial thigh. Postoperatively warm sitz bath after each bowel movement was advised. The patients were informed in detail about the presence of seton prosthesis and they were warned about the possible serous discharge that would continue until the seton dropped, and the wound healed. Data were recorded on the predesigned questionnaire and analyzed using SPSS version 16.

Results: Among 50 cases mean age was 41 years, $M: F$ was 4.5:1. Discharge from perianal sinus, pain, swelling and itching were common clinical presentation. All of the patients were discharged on the third postoperative day. None required readmission or needed narcotic analgesics after discharge. The average time for the seton to cut through the sphincter was 1 to 3 months. $28 \%$ had complete healing at 1 month and $66 \%$ at 3 months postoperatively. Flatus Incontinence was noted $16 \%$ cases followed by recurrence (6\%), liquid stool incontinence (4\%) and postoperative anal stricture was (2\%) of cases.

Conclusion: This study found that the seton is a safe and low morbidity option for the treatment of high and complex fistula-in-ano, having higher healing rates, with good quality of life. It can therefore be recommended as the standard treatment for complex fistula-in-ano.

[J Shaheed Suhrawardy Med Coll 2020; 12(1): 15-19] DOI: https://doi.org/10.3329/jssmc.v12i1.51613

1 Dr. Md. Armanul Islam, Resident Surgeon (Surgery), Shaheed Suhrawardy Medical College Hospital, Dhaka.

2 Dr. Md. Mahfuzur Rahman Khan, Medical officer (Surgery), Shaheed Suhrawardy Medical College Hospital, Dhaka.

3 Prof. Md. Mustafizur Rahman, Professor \& Head (Dept. of Surgery), Shaheed Suhrawardy Medical College Hospital, Dhaka.

4 Dr. S M Quamrul Akther, Associate Professor (Surgery), Shaheed Suhrawardy Medical College Hospital, Dhaka.

5 Dr. Md. Mozammel Hoque, Associate Professor (Surgery), Shaheed Suhrawardy Medical College Hospital, Dhaka.

6 Dr. Syed Masud Reza, Associate Professor (Surgery), Shaheed Suhrawardy Medical College Hospital, Dhaka.

7 Dr. Asma Bint Anowar, Resident Physician (Paediatrics), Shaheed Suhrawardy Medical College Hospital, Dhaka.

8. Dr. Shakila Akhter, Assistant Professor, Department of Pharmacology, National Institute of Cardiovascular Disease (NICVD), Dhaka

Correspondence to : Dr. Md. Armanul Islam, Resident Surgeon (Surgery), Shaheed Suhrawardy Medical College Hospital, Sher-EBangla Nagar, Dhaka-1207. Mobile- +8801718689788, Email- upal.arman@gmail.com

\section{Introduction:}

Fistula-in-ano is one of the commonly encountered surgical problems with the incidence for men to be 12.3 per 100000 and that for women 5.6 per $100000 .{ }^{1}$ Anal fistula is mostly nonspecific (idiopathic, crypto-grandular) with infection of an anal gland in the inter- sphincteric space as the initiating pathology. ${ }^{2}{ }^{4}$ However it may be associated with several specific conditions like Crohn's disease, tuberculosis, malignancy, lymphogranuloma venerium, presacral dermoid, rectal duplication, actinomycosis, trauma and foreign body. ${ }^{5} 6{ }^{7}$ Surgical management of fistula is challenging. Fistulotomy or laying open has long been considered the standard treatment for intersphincteric and low transsphincteric fistulas. ${ }^{8} 9$ Different types of Seton (string like material) are also used for management of fistula in ano, the cutting setons which incise through 
the tissue and non-cutting setons which facilitate the drainage of the tract. It takes three weeks to one year to cut through the tissue. 81011 Other surgical options are 'rectal advancement flap' (RAF) The success rate for RAF varies in the literature from 29 to $95 \% .{ }^{12}$ Cutaneous flaps: island flap ${ }^{13}$ or V-Y flap ${ }^{14}$, have been described with good results. Fibrin Glue seals the fistula tract in 30- 60 seconds. Success rates of this procedure ranges from 31-85\%. ${ }^{15} 16$ LIFT procedure is the ligation of the inter sphincter fistula tract first described by Rojanasakul in Thailand and success rate of the procedure was $58 \% .^{17}$

It is clinically evident that laying open a fistula tract is the most successful method of treatment and in most situations this can be done without any disturbance of continence. In case of high or complex anal fistula, where laying open method is not appropriate, another form of definitive repair will be required. In this situation seton application may be a safe and effective as well as the best option. So the aim of this study to find out the outcome of seton in the treatment of complex fistula in ano.

Material and methods:

This cross-sectional study was done in surgical units of ShSMCH and colorectal surgery units of BSMMU from September 2014 to August 2015. Fifty patients with high anal fistula having internal opening above dentate line and with multiple fistulas tract were included by purposive sampling. Patients with low anal fistula, fistula in ano associated with Crohn's disease, active abdominal tuberculosis, carcinoma of rectum, previous radiation therapy, with recurrent fistula in ano and in whom the internal opening could not be located were excluded. Before enrollment informed consent were taken. All the procedures were performed under spinal anaesthesia in lithotomy position. The treatment method was decided during the operation based on the relationship of the fistulous tract with the sphincter muscles. After initial evaluation, the external and internal opening were located using a blunt-tipped, flexible metal probe and hydrogen peroxide injection along the tract. The portion of the tract outside the sphincters was laid open and curetted, as were any lateral secondary tracts. A non absorbable suture (e.g. prolene 0) was inserted through the external opening of fistula tract by using a buttonhole probe in a doublestrand fashion. The skin and anoderm overlying the fistulous tract were incised. This double-strand seton was then tied over itself on the sphincter without excessive tension. The long end of each suture was tapped to the patient's medial thigh. Postoperatively warm sitz bath after each bowel movement was advised. The patients were informed in detail about the presence of seton prosthesis and they were warned about the possible serous discharge that would continue until the seton dropped, and the wound healed. The patients with co-morbid conditions like diabetes mellitus, hypertension, ischaemic heart disease and COPD were treated for the condition first and then reassessed for fitness for surgery.

Repeated examinations were carried out at weekly interval for 1 month and fortnightly for 3 months . At each visit, the position of seton was assessed and tightened progressively. The data of previous anal operation, history of fecal incontinence before and after seton treatment, wound healing and recurrence of anal fistula were recorded. Patients were followed up upto three months after operation. Postoperative pain was evaluated with a visual analog score (VAS) on the first and eighth postoperative days. The days required for the seton to cut through and drop were recorded, as well as complications and complete healing rates at 1 and 3 months, respectively. Preoperative and postoperative (at 3 months) anal incontinence scores were assessed. Therefore, the primary end point was fistula healing. The secondary end points were changes in baseline incontinence scores, complication rate, and time required for complete healing.

\section{Statistical analysis:}

Analysis was performed with SPSS software, versions 22.0. Continuous data that were normally distributed was summarized in mean, standard deviation, median, minimum and maximum. Skewed data was presented in the maximum, upper quartile, median, lower quartile, minimum and number of observations. Categorical or discrete data was summarized in frequency counts and percentages. For end points analysis, chi square test was used for categorical variables.

\section{Results:}

Among 50 study cases mean age was 41 ears and M: F was 4:1, majority of them were day labor and farmer [Table-1]. Purulent discharge from fistula with pain were common clinical presentation, $80 \%$ cases had history of spontaneous rupture of anal abscess. Few cases had associated comorbidities DM (8\%) and COPD (8\%) [Table 2]. Fistulogam was done among $48 \%$ cases [Table-3]. Postoperative pain was noted by visual analog scoring system. In $1^{\text {st }}$ postoperative day majority of the $25(50 \%)$ patient's complaint of moderate pain (Score 4-6) followed by $18(36 \%)$ had severe pain (score $7-10)$ and $7(14 \%)$ had mild pain (score 1-3). In $8^{\text {th }}$ postoperative day the majority of the patients $(76 \%)$ had mild pain, $12(24 \%)$ had moderate pain and none had severe pain (Figure-1). The average time of the seton to cut through the sphincter was 1 to 3 months, $28 \%$ had complete healing by 1 month and $66 \%$ at 3 months postoperatively. Acute retention of urine (32\%), flatus 
incontinence $(16 \%)$, bleeding $(6 \%)$, liquid stool incontinence ( $4 \%)$ and abscess formation $(2 \%)$ were found common post-operative complication. Worsening of baseline continence was noted in 10 patients of which and was noted in 2 patients (4\%). Out of 50 patient's recurrence of the fistula was noted in 3 patients $(6 \%)$ and anal stricture was noted in 1 patient ( $2 \%$ ) [Table IV].

Table 1

Socioeconomic profile among the study cases $(N=50)$

Variables Frequency $(\%)$

\section{Age (Years)}

21-35

$17(34 \%)$

$36-50$

$27(54 \%)$

$51-65$

$6(12 \%)$

Sex

Male

Female

$41(82 \%)$

\section{Occupation}

Labor

$16(32 \%)$

Farmer

$10(20 \%)$

Shopkeeper

Housewife

$7(14 \%)$

$7(14 \%)$

Service holder

$5(10 \%)$

Student

$3(6 \%)$

Maidservant

$2(4 \%)$

\section{Table-II}

Clinical profile among the study cases $(N=50)$

Symptoms \& signs

Frequency (\%)

Discharge, swelling \& pain

$08(16 \%)$

Discharge \& pain

$12(24 \%)$

Discharge \& itching

$09(18 \%)$

Discharge

$21(42 \%)$

Type of discharge

Purulent

$33(66 \%)$

Seropurulent

$11(22 \%)$

Serosanguinous

Previous ano-rectal abscess

Spontaneous ruptured

Incision \& drainage

Associated co-morbid conditions

\begin{tabular}{lc} 
COPD & $4(8 \%)$ \\
DM & $4(8 \%)$ \\
HTN & $2(4 \%)$ \\
Pulmonary TB & $1(2 \%)$ \\
\hline
\end{tabular}

Table-III

Radiological Examination

\begin{tabular}{lc} 
Investigation & Frequency (\%) \\
\hline Fistulogram & $24(48 \%)$ \\
MRI & $07(14 \%)$ \\
EUS & not done \\
X-ray chest & $50(100 \%)$ \\
\hline
\end{tabular}

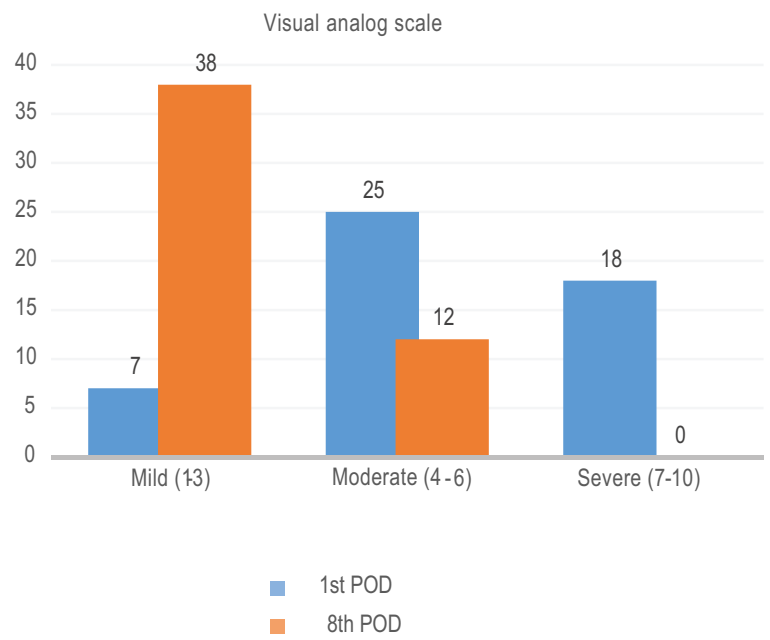

Figure 1: Shows visual analog scale score of the patients

Table-IV

Post-operative Outcome among the study cases

Outcome

Frequency $(\%)$

During of healing

$<1$ month

$14(28 \%)$

$<3$ months

$33(66 \%)$

No healing

$3(6 \%)$

\section{Early complications}

Urinary retention (catheterization not needed) 12(48\%)

Urinary retention (Catheterization required) $\quad 4(8 \%)$

Bleeding 3(6\%)

Flatus incontinence $\quad 8(16 \%)$

Liquid stool incontinence 2(4\%)

Abscess formation $\quad 1(2 \%)$

Late complication

Recurrence $3(6 \%)$

Stricture $1(2 \%)$ 


\section{Discussion:}

Management of complex fistula in ano is a surgical challenge. It is notorious for its chronicity, recurrence and frequent acute exacerbations. Complex and high anal fistula disease is not uncommon in adults and has its maximum incidence between third and fourth decades of life. $^{2} 18$ The age distribution (mean 41 year ) and male predominance $(82 \%)$ seen in this study is in agreement with the other studies. ${ }^{23} 192021$ In this study most of the patients were from low socioeconomic group which indicate poor personal hygiene and ignorance. All of the patients have previous anorectal abscess and it seems to be the most common cause of complex fistula in ano. The main presenting complaints of the patients (Discharge, pain, swelling and itching) in this study are also in agreement with other study. ${ }^{2}$

Prolene- 0 has been used in this study as cutting seton. This is durable, non-toxic/non-allergic and is easily available in sterile packing at a reasonable price. There are several other materials used as seton as mentioned in introduction, but whatever the material is, recurrence and incontinence rate is mainly dependent on expertise and judgement of the surgeon. ${ }^{22} 23$

Usually the healing after a seton procedure is uneventful, though minor control problems may occur in a variable number of patients. This study found $16 \%$ of flatus incontinence and $4 \%$ of liquid stool incontinence in early postoperative period. All the patients were recovered fully within one month of operation. The incidence of incontinence following seton insertion reported by other studies ranged from $0 \%$ to $47 \%$. On the other hand, Isbister conducted a study at King Faisal Specialist hospital, reported incontinence in $47 \%$ of patients. Similarly, in 2008, Chaung et al, conducted a study on 112 patients with complex anal fistula. They reported incontinence of $24.1 \%{ }^{3}$ Incontinence rate of this study can be attributed to meticulous surgical technique whereby sphincter remains intact. Low recurrence rate may due to proper identification of internal opening and the extensions of fistula tract. The use of seton was not associated with significant pain. The postoperative VAS score were low and none of the patients were needed narcotic analgesics after discharge.

This study has found $6 \%$ recurrence rate in 50 patients treated with cutting seton for high and complex anal fistulas. Different studies have shown different results with recurrence rate ranging from 0 to $18 \%{ }^{22}{ }^{24}$ Mac Courty in his study reported only $4 \%$ recurrence after treating complex high fistula-in-ano, with cutting seton without preliminary internal sphincterotomy. Guere conducted a study over nine patients with high fistula-in-ano, reported no recurrence. ${ }^{3}$ Thus the result of this study correlates with the result of other studies.

The preliminary results of this series have shown that the seton is a promising tool for the treatment of high and complex anal fistulas. The follow-up period is short only three months and the success rate appears to be high. This method is apparently free from significant complications. Anal contour is largely preserved, and baseline continence is not significantly disturbed. Moreover, $94 \%$ healing was achieved within three months. The remaining $6 \%$ was not healed within follow up period. The study is a single-arm study with no comparison group.

\section{Conclusion:}

This study concluded that the seton is a safe and low morbidity option for the treatment of high and complex fistula-in-ano. As compared to other modalities of treatment, seton therapy is cheaper, easier to perform, and follow-up, having reasonably higher healing rates, with good quality of life. It can therefore be recommended as the standard treatment for complex fistula-in-ano.

\section{References :}

1. Sainio P. Fistula-in-ano in a defined population. Incidence and epidemiological aspects. Ann Chir Ggnaecol. 1984; 73: 219-24

2. Qazi AR, Memon JM, Solangi RA, Naqvi SQH. outcome analysis of partial fistulotomy with seton. Pakistan Journal of Surgery 2008; $24: 15-18$

3. Aman Z, Naeem M, Ahmad S, Aslam R, Ahmed T, Shamsi H.The effect of seton cut through technique on continence and recurrance after treatment of high fistula-in-ano. Journal of Postgraduate Medical Institute 2009; 23 :251-3.

4. Parks AG. The pathogenesis and treatment of fistula in-ano. $\mathrm{Br}$ Med J 1961;1: 463 -9.

5. Nelson RL, Prasad ML, Abcarian H. Anal carcinoma presenting as peri-rectal abscess or fistula. Arch Surg 1985; 120: 632-5.

6. Pye G, Blundell JW. Sacrococcygeal teratoma masquerading as a fistula-in-ano. J Roy Soc Med 1987; 80: 251-2.

7. Narashimharao KL, Patel RV, Malik AK, Mitra SK. Chronic perianal fistula: Beware of rectal duplication. Postgrad Med 1987; 63: 213-4.

8. Akhtar M. Fistula in Ano - An Overview. Journal of International Medical Science Academy 2012; 25 :53-55.

9. Oh, C. Management of high recurrent anal fistula. Surgery 1983; $93: 330-332$.

10. Stonesifer GLJ, Murphy GP, Lombardo CR. Amer. J. Surg 1960; 100: 666.

11. Milligan ETC, Morgan CN. Surgical anatomy of the anal canal with special reference to anorectal fistulae. Lancet 1934; 2.

12. Rickard MJFX. Anal abscesses and fistulas. ANZ J. Surg. 2005; 75: 64-72.

13. Eisenhammer S. The final evaluation and classification of the surgical treatment of the primary anorectal cryptoglandular intermuscular (intersphincteric) fistulous abscess and fistula. Dis.Colon Rectum 1978; 21: 237-54. 
14. Parks AG, Gordon PH, Hardcastle JD. A classification of fistulainano. Br. J. Surg. 1976; 63: 1-12.

15. Amir M. Current trends in management of Fistula- in- Ano: Can we minimize recurrence? Journal of Surgery Pakistan (International) 2011; 16:47-49.

16. Garcia-Aguilar J, Belmonte C, Goldberg SM, Madoff RD. Anal fistula surgery. Factors associated with recurrence and incontinence. Dis Colon Rectum 1996; 39:723-9.

17. Goodsall DH, Miles WE. Diseases of the Anus and Rectum. London: Longman, 1900.

18. Ratto C, Gentile E, Merico M et al. How can the assessment of fistula-in-ano be improved? Dis. Colon Rectum 2000; 43: 137582.

19. Sudol-Szopinska I, Jakubowski W, Szczepkowski M. Contrast enhanced endosonography for the diagnosis of anal and anovaginal fistulas. J. Clin. Ultrasound 2002; 30: 145-50.
20. Sudol-Szopinska I, Jakubowski W, Szczepkowski M, Sarti D. Usefulness of hydrogen

peroxide enhancement in diagnosis of anal 43. Bartram C, Buchanan G. Imaging anal fistula. Radiologic Clin. North Am. 2003; 41: 443-57.

21. Bartram C, Buchanan G. Imaging anal fistula. Radiologic Clin. North Am. 2003; 41: 443-57.

22. Madsen SM, Myschetzky PS, Heldmann U, Rasmussen OO, Thomsen HS. Fistula in ano: evaluation with low-field magnetic resonance imaging (0.1 T). Scand. J. Gastroenterol. 1999; 34:1253-6.

23. Scholefield JH, Berry DP, Armitage NC, Wastie ML. Magnetic resonance imaging in the management of fistula in ano. Int. J. Colorectal. Dis. 1997; 12: 276-9.

24. Zbar AP, de Souza NM, Piuni R, Kmiot WA. Comparison of endoanal magnetic resonance imaging with surgical findings in perirectal sepsis. Br. J. Surg. 1998; 85:111-14. 